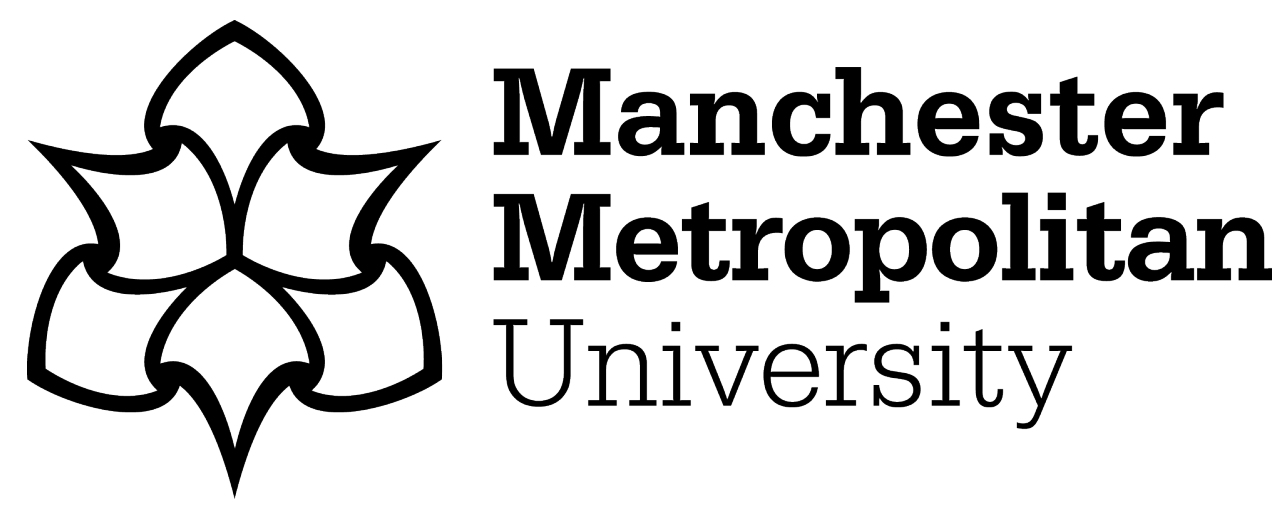

Gabi, J ORCID logoORCID: https://orcid.org/0000-0003-3629-0719 and Sharpe, S (2021) Against the odds: an investigation into student persistence in UK higher education. Studies in Higher Education, 46 (2). pp. 198-214. ISSN 0307-5079

Downloaded from: https://e-space.mmu.ac.uk/624071/

Version: Accepted Version

Publisher: Taylor \& Francis

DOI: https://doi.org/10.1080/03075079.2019.1626364

Please cite the published version 


\title{
Against the odds: an investigation into student persistence in UK higher education
}

\author{
Josephine Gabi \& Sarah Sharpe
}

To cite this article: Josephine Gabi \& Sarah Sharpe (2019): Against the odds: an investigation into student persistence in UK higher education, Studies in Higher Education, DOI:

10.1080/03075079.2019.1626364

To link to this article: https://doi.org/10.1080/03075079.2019.1626364 


\title{
Against the odds: an investigation into student persistence in UK higher education
}

\author{
Josephine Gabi ${ }^{\mathrm{a}}$ and Sarah Sharpe ${ }^{\mathrm{b}}$ \\ ${ }^{a}$ Faculty of Education, School of Childhood, Youth and Education Studies, Manchester Metropolitan University, \\ Manchester, UK; ${ }^{b}$ Faculty of Education, Department of Health and Wellbeing, University of Wolverhampton, \\ Wolverhampton, UK
}

\begin{abstract}
This article focuses on student persistence in Higher Education. It examines qualities that enable students to persist in their studies despite the challenges they face, and key factors interplaying with and affecting these qualities. This study utilised the explanatory mixed-methods approach. It comprised a faculty-wide survey which explained the relationships between and across variables. Focus group interviews explored significant predictors of students' persistence. Results from this study showed that, among other things, key drivers of student persistence were personal optimism, academic engagement, and positive relationships. Students' decision to stay on and complete their studies determines their persistence; but there also remains a major role to be played by institutions. Successful student persistence tends to be a result of an intricate interaction between the student's personal factors and their environment - and the institution is a key component of that environment.
\end{abstract}

\section{KEYWORDS}

Persistence; retention; mixedmethods; students; higher education

\section{Background}

Most of what we know about university student trends has been influenced by retention research conducted with students who have dropped out from the university (Habley, Bloom, and Robbins 2012). Whilst this provides information about why students leave (Yorke and Longden 2008), it tells us very little about why those who persist remain. The central argument of the current study is that, as much as the negative aspects of student retention and progression data provide diagnostic insights, perhaps shifting focus to what is right with the present picture may offer an antidote to the identified problems. Much can be learned from students who persist and succeed that can be used to draw up strategies for promoting persistence qualities identified in these students. Focusing on student persistence, rather than retention, acknowledges the power and initiative which reside within students to persist towards their goals and ideals in a Higher Education (HE) context.

Against this backdrop, this study sought to occupy an alternative argument position to this skewed dominate discourse within the student retention and progression field. While the dominant discourse's main interest is in what institutions do to 'retain' students - implying that the student is passive - the aim of this study was to go beyond this and consider other factors which allow students to persist - implying that the student is active and in control. Particular curiosity focused on what drives some students' decision to stay on when others in similar conditions leave, hence the adoption of the term persistence in lieu of retention. 
In the current dispensation of the commodification of education, it has become even more important to use student numbers - not only of those who join, but those who stay on - as a proxy indicator of institutional success (Hamblet 2015). Thus, students' decision to stay on a university programme until completion rudimentarily symbolises customers who have purchased a product and decided to keep it. In this context, retention rates become all the more important to Higher Education Institutions (HEls) as they appear to 'damage the reputation of a university and create long-term implications for attracting new students' (Smith, Therry, and Whale 2012, 92). According to Hamblet (2015), student retention and progression trends in most UK institutions are generally concerning; the data indicates that more still needs to be done to improve the trends. Yet, more focus thus far appears to have been on what is wrong with the current trends at the expense of what is right (Reason 2009).

Therefore, the present study sought to answer the following research questions:

(1) What challenges do students face and how do these challenges affect their studies?

(2) What strategies do students adopt to enable them to overcome these challenges and persist in their studies?

\section{Methods and methodology}

The project was born initially out of collaborative meetings with two research colleagues across two university campus sites who discovered a mutual passion for the student experience. As shared goals emerged, research plans were combined into a joint project across the two sites. A mixed-methods approach was adopted, drawing on both quantitative and qualitative research methods, underpinned by the pragmatist paradigm (Teddlie and Tashakkori, 2003). The pragmatist paradigm relies on 'shared meanings and joint action' (Shannon-Baker, 2016, 322) and 'transferability' of findings to different contexts (Jensen 2008). Thus, this pragmatic and complementary approach to research enabled shared meanings of quantitative and qualitative data through data integration. This afforded a broader understanding of student persistence, progression, success and retention. Callon and Law (1995) note that nothing exists as discrete or detached entities, but networked and relationally defined where, for example, students' pre-entry attributes, institutional ethos, student support services, can be considered in examining the fluidity and conceptual relationality between them in shaping student persistence.

\section{Theoretical framework}

The study utilises Tinto's $(1997,615)$ interactionalist model, illustrated in Figure 1, to make sense of the data in relation to the complex factors that impact on student persistence.

Tinto's interactionalist model views student persistence as a function of the fit between the student's pre-entry attributes, goal commitments, effort and institutional experiences. The interaction between these factors shapes the student's capacity to persist and succeed in complex ways as they influence their understanding of reality, their educational experience and consequently their determination to complete (Thomas 2002). Social and academic integration is also viewed as having a significant impact on student persistence (Ginn et al. 2015). Considering the complex interactions of factors within the model and the demands of university life, students' success could depend on how well they adapt to and integrate with the institutional environment. Therefore, in light of this, if a student enters an institution and feels that they do not fit into the institution, they may feel more inclined to withdraw. However, Thomas $(2002,431)$ contends that if the institutional environment embraces diversity and is 'inclusive and accepting' of differences, students in turn will 'respect their own practices and knowledge', and consequently persist.

It seemed reasonable to utilise Tinto's model of persistence as a framework to make sense of the study. 


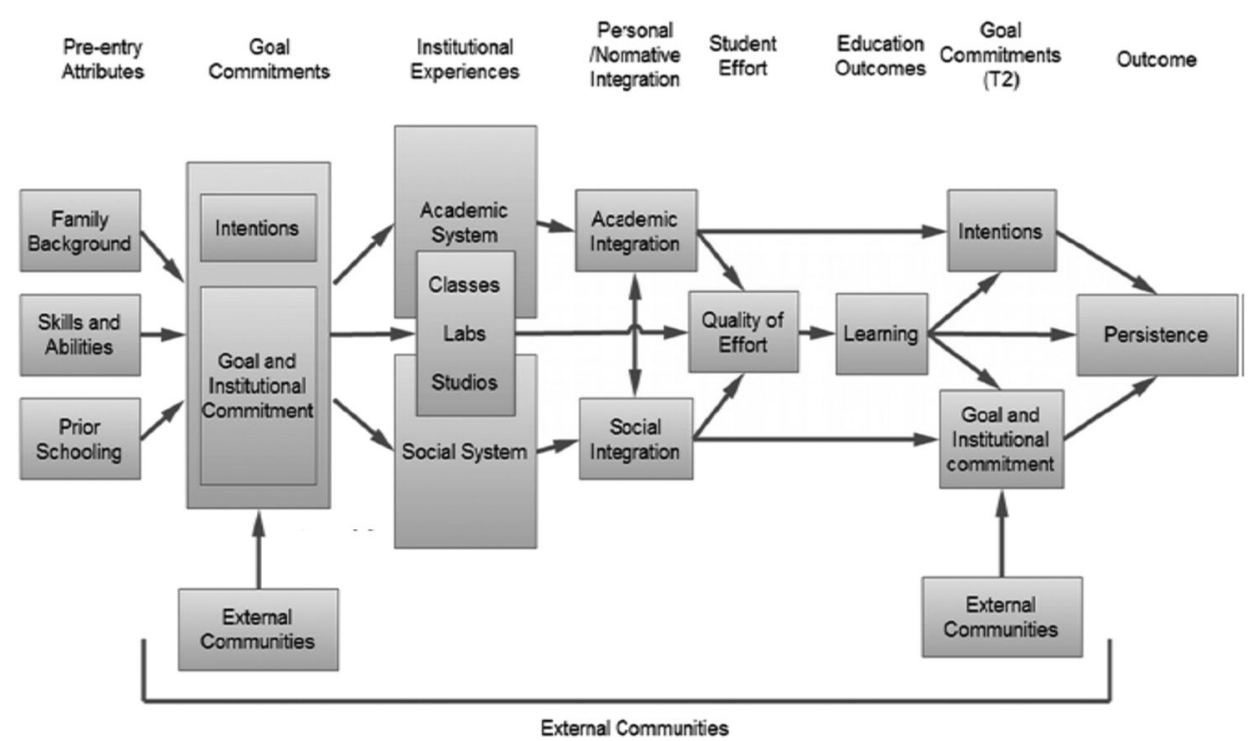

Figure 1. Interactionist model of persistence.

\section{Methods}

Mixed qualitative and quantitative methods were adopted across two Faculty of Education sites within the university. A survey was conducted with 68 students at the larger site, and three semistructured focus group interviews with a total of 24 students at the rural site. The project had a two-fold purpose:

- To identify factors affecting student persistence and progression

- To allow research to inform and transform practice

\section{Piloting and participant selection}

On both sites, exploratory questions were piloted on a number of colleagues and students to explore possible variables to include in the questionnaire and interviews; the design of variables was also drawn from the literature, and questions adjusted accordingly.

The survey questionnaire was deployed via email to 400 students at the main site. A sample $(N=$ 68) responded to the survey, representing a response rate of $17 \%$. Participants were drawn from a range of departments as follows: $.01 \%(N=1)$ Youth and Community, 33.8\% $(N=23)$ Education Studies, $27.9 \%(N=19)$ Primary Education and $36.8 \%(N=25)$ Early Childhood Studies.

At the rural site, all 61 students within the Early Childhood Studies department were invited to participate in a series of focus groups across the three year groups (first, second and third year students). A sample $(N=24)$ responded positively as follows: $58 \%(N=7)$ in Year $1,50 \%(N=10)$ in Year 2 and $24 \%(N=7)$ in Year 3. This represents a response rate of almost $40 \%$.

\section{Ethical considerations}

Like most studies, persistence research throws up many ethical issues meriting consideration. Darlington and Scott (2002) note that no research is completely free from risk but that the benefits of the research should be balanced against possible risks when making ethical decisions. Thus, the study involved an ongoing reflection on the research process which, as observed by Gallagher 
et al. (2010), is 'the hallmark of ethical practice' and a vital part of research. Full information about purpose, process of the study and reporting of findings was provided to participants prior to commencing the investigation to enable them to give their informed consent. Participants were also informed of their right to withdraw without obligation, and that interview responses would be audio recorded and used for analysis of the research project. They were assured that their identities would be anonymised and that any audio recordings would be securely stored in accordance with the university's data protection protocols.

\section{Data presentation and analysis (quantitative survey study)}

Exploratory Factor Analysis was utilised as a data reduction technique in order to make sense of the eighty-nine variables in the questionnaire survey. This was useful for assembling variables into meaningful categories for analysis, and helped in the identification and categorisation of factors influencing variables whilst also grouping variables that go together. Thus, data analysis and interpretation was approached from an interpretive perspective which acknowledges that statistical modelling of variables on its own, although it may help shed some light on the subject, cannot be viewed from a linear logic which attempts to pin down or fix students' complex and fluid experiences whilst wading into ambiguous 'epistemology of causality' (Babones 2016, 464). This was based on the view that reality is imperfectly apprehensible, hence the need to consider the fluid and complex factors that shape student persistence. Therefore adopting an interpretative approach to quantitative data analysis and interpretation of findings is not about identifying causality or fixing truths but rather, as suggested by Sobh and Perry $(2005,1200)$, 'social phenomena are by their nature fragile, so causal impacts are not fixed but contingent upon their environment'. This is about resisting the possibility of representation by overly quantifying student experience whilst also acknowledging that statistical modelling of variables 'must not be rejected definitely, of course, but the tranquility with which they are accepted must be disturbed ... and the justifications of which must be scrutinised' (Foucault 1972, 25). It seemed reasonable to acknowledge that a range of dynamic factors impact on students' ability to persist with their studies and that these subjective factors may not be entirely quantifiable - which justifies the mixed-methods approach.

Exploratory Factor Analysis made it possible to determine relationships and patterns emerging from the data as presented below. In the survey, a Likert Scale was used to measure participant responses, from 1 (strongly disagree) to 5 (strongly agree). In each table, factors are identified by the largest loading as these were helpful in determining the strength of relationships. For example, under 'personal attributes', the variable 'I am an optimistic person' best represented Factor 1.

\section{Factor loading and interpretation}

Three factors were identified and these were grouped according to distinct but interrelated clusters of variables beginning with the largest loading. These were personal attributes, academic integration and network of support. Personal attributes, as observed by Mount et al. $(2005,447)$ are relevant to students' capacity to persist as these tend to 'influence choices individuals make about which tasks and activities to engage in, how much effort to exert on those tasks, and how long to persist with those tasks'. That means, students' decision to stay on the course may be influenced by their personality attributes as this reflects what they will do (characteristic adaptation) in response to different circumstances as opposed to what they can do (cognitive abilities). Thus, personal attributes predispose individuals to act in a particular way across different life events (Oseguera and Rhee 2009). Institutional practices and processes were also of interest in terms of how these impact on student academic integration and their decision to stay on. This was based on the view that students who feel academically integrated are likely to show commitment to their studies and institution. In 
addition, institutional and external communities tend to be made up of a network of people whose support may be key to students being persistent. These factors are presented below:

\section{Factor 1: personal attributes}

\begin{tabular}{ll}
\hline Personal attributes & .905 \\
\hline I am an optimistic person & .899 \\
I am dependable & .885 \\
How would you rate your openness to new experiences? & .821 \\
I am comfortable seeking support from others & .789 \\
How would you rate your intellectual curiosity? & .778 \\
How frequently do you use the university pastoral support structures? & .754 \\
\hline I handle disappointment well & \\
\hline
\end{tabular}

Students in this sample exhibited diverse personal attributes which reflected their characteristic pattern of feelings, behaviour and thought processes. Findings of this study indicated that optimism, which epitomises an individual's ability to use more problem focused coping strategies, positive reframing and re-interpretation, was the most important personal attribute that predicts persistence. Optimism, as observed by Hakimi, Hejazi, and Lavasani (2011), is a buffer for personal and academic challenges. Students who are optimistic are likely to seek emotional and academic support from family, friends as well as university tutors. These students are also likely to handle disappointing outcomes in a positive way. In the literature (e.g. Stumm, Hell, and Chamorro-Premuzic 2011), individuals who are open to new experiences tend to be intellectually curious and are adaptable. Students who scored highly in this category will require constant exposure to new ideas and thinking in order to stimulate their intellectual curiosity and generate interest and learning. Additionally, prior exposure to instances that require greater adaptability enhances students' openness to new experiences. Similarly, Farquhar et al. (2006, 11) suggests that students who are open to new experiences also tend to be prepared to overcome obstacles and may consider 'failure on a task as a new point of departure rather than a judgement of them as a learner'. Thus, student persistence is further enhanced by students' ability to handle disappointment.

\section{Factor 2: academic integration}

Academic Integration

How frequently do you contact your lecturers by email?

The significance of students' academic integration to university life has been highlighted in the literature (e.g. Tinto 2017). Results showed that students frequently contact tutors by email. Students reported that they effectively use tutor feedback to improve on the quality of their work. This may also relate to students feeling that they have sufficient support for their assignments. It can be argued that timely, formative assessment, constructive feedback and feedforward help students capitalise on their learning whilst instilling in students a positive work ethic, self-discipline, academic achievement and persistence (Graham and Diez 2015). In addition, student engagement with learning management systems such as Moodle provides flexible continuous learning opportunities that may foster intellectual integration as students are able to work at their own time, pace and place. 
Support network

I have access to a supportive network of people

Most students highlighted having access to a supportive network as a significant factor to their ability to persist with their studies. Supportive networks both within the institution and externally help them gradually integrate networks that may help foster their sense of social and academic belonging particularly in their first year of study where students are likely to feel lonely. Tinto (2017) notes that the interaction between academic and social dimensions of student experience effectively influences their decision to stay on or drop out. Therefore, both learning communities created by the institution and those set up by students themselves are likely to enhance their persistence qualities. Students may find comfort interacting with peers who share the same religion as them but as they progress with their studies, they may go beyond their peers and seek support from, for example, careers services and personal tutors. Calcagno, Walker, and Grey (2017) note that personal tutors have a capacity to develop andragogic encounters that bring into dialogue the needs, lives and aspirations of students with broader socio-cultural, economic, political issues and their studies. This acknowledges the complexities of persistence as it is shaped by complexly interwoven factors such as an individual's personal attributes; environmental factors and how these interact at any given time. Family approval of degree choice also plays a significant role in enhancing student persistence; students' motivation is likely to be strengthened when their family is supportive of their degree and able to appreciate the demands of HE study.

\section{Data presentation (qualitative focus group study)}

In the rural study, three focus group interviews took place with students from Year 1, 2 and 3, each following the same format. In Part 1, students paired up to interview each other using a scheduled set of questions, each summarising the other's responses on a prepared template. In Part 2, the students joined together in a focus group interview, sharing reflections which were digitally recorded. The methods used allowed in-depth, multi-faceted explorations of complex issues that affect student persistence, progression and success (Yin 2003). Questions were designed to explore students' ideas of persistence, the challenges and barriers that they faced as students, and the strategies that they adopted to overcome these barriers. Students in each year group were highly responsive to the questions asked. The split method of interviewing was designed to allow students an opportunity to relax into the session through initial paired discussions prior to the main focus group interview.

The following section presents the findings question by question and includes some verbatim quotations from participants; charts are used to portray similarities and differences in perceptions of students across the three year groups. Analysis and integrative discussion follow in a later section.

\section{Part 1: issues and challenges affecting persistence}

Q1: What does 'persistence' mean to you personally in terms of your university study?

Four key themes emerged from the data, as shown in Figure 2 by year group.

The overarching theme - across all three groups - was one of determination and willpower despite difficulties faced, of 'never giving up', 'sticking it out' and 'carrying on when it's easier to give up or it's really hard'. There was a sense, too, that students felt they were in this for the 'long haul', 


\title{
WHAT DOES PERSISTENCE MEAN TO YOU?
}

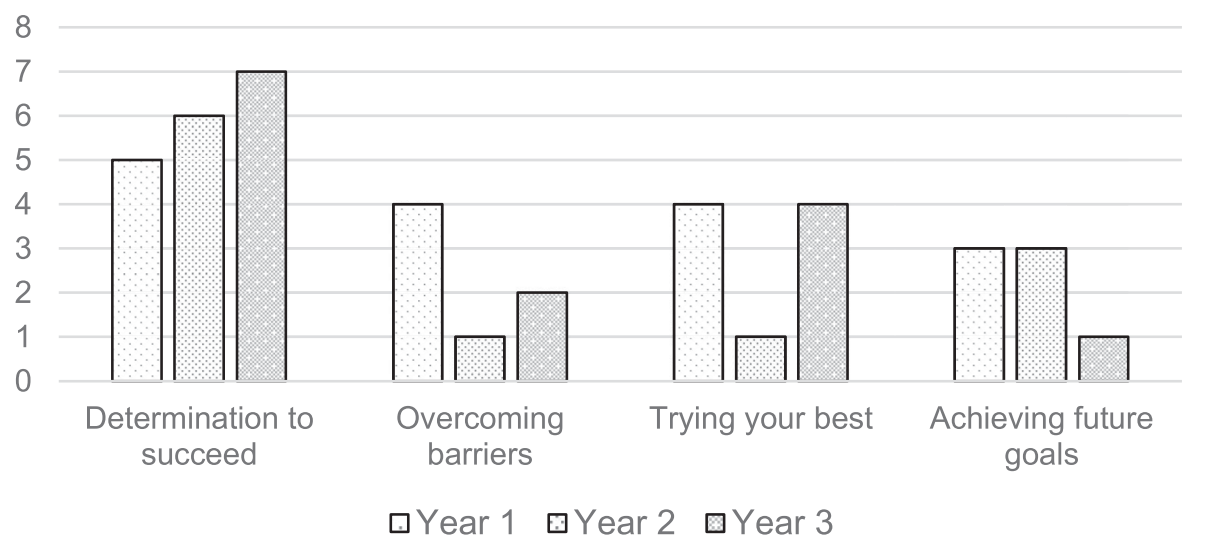

Figure 2. What does persistence mean to you?

or as one Year 3 student explained: 'Learning that it takes time - a gradual process'. To many students, persistence was also about trying hard to achieve one's best, to do well in assignments, to be eager to learn and engage, to be self-motivated and not lose focus. To others, it was about achieving goals and reaching potential and keeping in view the job they want at the end of their studies: 'Knowing you'll get a degree at the end'.

Another third year student articulated what the term 'persistence' meant to him:

\begin{abstract}
Being able to self-motivate and set mini goals for assignments and deadlines; making sure I give myself 'free' days to switch off from work rather than trying to work every day and suffer burn out. It helps me keep persistent in my work and not lose focus... knowing it will be worth it in the long run.
\end{abstract}

Students also felt the term persistence related to overcoming barriers and obstacles, ignoring distractions and not letting these affect their work. There was mention of the distractions of personal issues and family commitments, and in one case the challenge of overcoming the 'obstacle' of dyslexia.

Q2: What are some of the factors that have caused you most stress or challenge as a student?

Data gathered were sifted and broadly categorised into nine themes. Analysis revealed that students in individual year groups were generally agreed on the issues that affected them, but these issues differed widely between final year students and the rest, as can be seen from Figure 3.

It is evident that the pressures of working at HE level - with its focus on academic study, assignment writing, deadlines and time management - dominated the discussions of Year 1 and 2 students. This may be due to the adjustment required of students as they transition from a traditional sixthform college environment to a university degree programme with its academic demands and increased amount of independent study, and possible decline in grades and academic performance. One Year 3 student reflected on her initial transition thus:

I think it's a shock because it's a massive jump, there's a massive shock from A levels to first year. When you probably first hand in your assignment you might not get the grades you expect but you can't get put down by that because it's just your first year, you need to get to terms with things.

Year 1 students struggled mostly with assignment writing and meeting deadlines - perhaps some of the most difficult skills to master on transition to HE. The transition from first to second year was also challenging for most Year 2 students, with increased workload, wider reading requirements and more challenging assignments. They spoke of difficulties in referencing and in particular wider 


\section{FACTORS CAUSING MOST STRESS OR CHALLENGE}

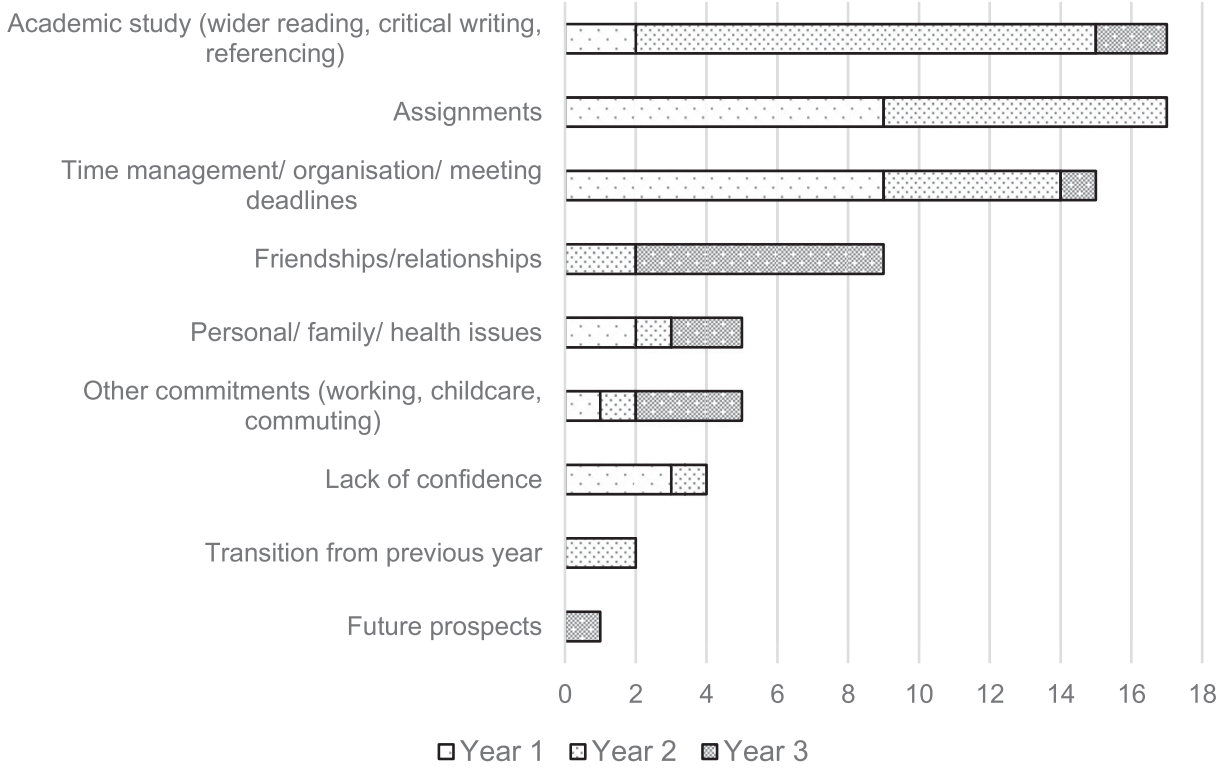

Figure 3. Factors causing most stress or challenge.

reading - knowing how much to read, how to select appropriate material, how to sift and skim-read and how to read and write critically. Confidence issues emerged as a significant factor and added to stress levels: some spoke of feeling unable to approach tutors for help, others of lacking confidence in making friends or a debilitating fear of having to speak up in front of their peer group in case they 'got it wrong' or were laughed at.

By contrast, this lack of confidence seemed to give way to increasing levels of self-assurance in Year 3, alongside improved time management and an absence of stress over academic issues. Students reflected rather on issues of friendships and relationships, and other personal commitments. This notable shift in focus may be due to increased experience and maturation, and to a growing confidence in asking tutors for help or direction, and taking on board and applying tutor feedback. It is feasible to conclude that by the time these students had reached their final year, they had largely mastered the techniques and skills required of HE study, and had settled into a comfortable rhythm of academic life.

Q3: How did these challenges affect your studies?

In this final stage of Part 1, it was interesting to note how students responded to stress factors in different ways. Some students (mostly in Years 1 and 2) admitted that stress factors had 'set them back' and had had a detrimental effect on their studies. Conversely, others (mostly in Year 3) spoke of the positive impact of the challenges.

Figure 4 demonstrates the percentage of negative versus positive impact of challenges by year group:

It is evident that as students moved through their transitional journey into their final year, they appeared to become more resilient and better able to cope with challenges. The effect on their studies at Year 3 was almost entirely positive (86\%). For these students, concerns appear to lessen as their journey progresses and they become increasingly confident in their own academic abilities and in asking tutors for clarification and support. Even when they had encountered significant stress factors, they seem to have developed resilience strategies to help them overcome these, or taken steps to remedy difficult situations. 


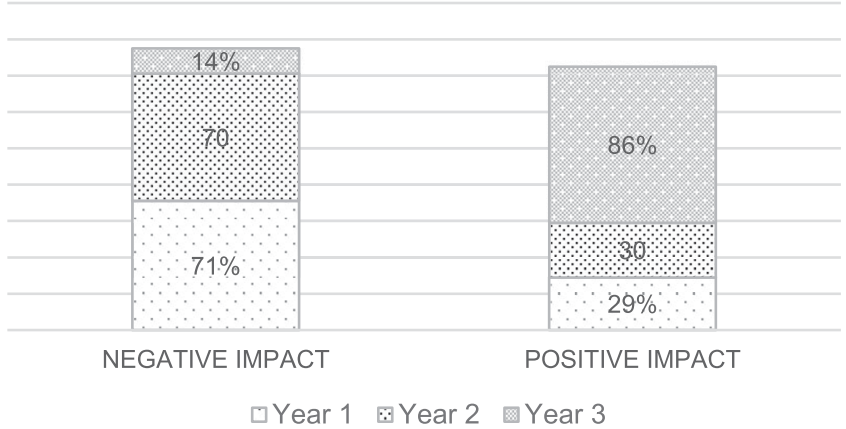

Figure 4. Effects of challenges on studies.

One of the most significant themes for Year 2 and 3 students was that of friendships and the effect these had had on their studies - both negative and positive. Several third year students spoke of the 'unpleasant time' they had experienced living with certain students, and of the difficulties they had encountered through forging the 'wrong' friendships in Year 1. These had proved to be a distraction and had a negative impact on their studies and academic progress. Conversely, many acknowledged how the development of positive friendships had proved to be fruitful and confidence-building. In all cases these new friendship groups had been successful in doubling up as effective study groups and in enhancing academic progress as well as an individual sense of belonging and involvement.

\section{Part 2: factors and strategies enabling persistence}

Q4 What strategies did you adopt that were effective in helping you persist despite the challenges you faced?

Strategies adopted by students to enable them to persist in the face of challenges were broadly categorised into four main areas:

- Personal

- Academic

- Relational (friends/family)

- Relational (tutors)

Specific factors and strategies were raised within each year group, but there were also key themes common to all groups, as can be seen in Figure 5.

Students spoke of becoming resilient, learning how to manage stress, knowing when to take a break, of being motivated through self-belief to push forward. A move towards greater self-reliance, self-determination and a resolve to succeed was evident by year 3 . In this final year group there was much discussion around how the university experience had changed them radically, helped them mature and 'become their own person'. One final year student expressed her journey thus:

You learn as well, when you go through uni, even though you don't believe it at the time, you know you're going to get through, knowing you've got an assignment ahead and you're going to get through, becoming more determined, seeing light at end of tunnel, one last push! And I think the more you do that through Level 4 and 5 the more you think 'OK I can do this'. These experiences make you more resilient, more determined despite the pressure.

Several raised the issue of the pressures of employment, of how difficult it had been to juggle time when there was a need to work to earn money in times of financial hardship, and of the self-discipline 


\section{FACTORS \& STRATEGIES ENABLING PERSISTENCE}

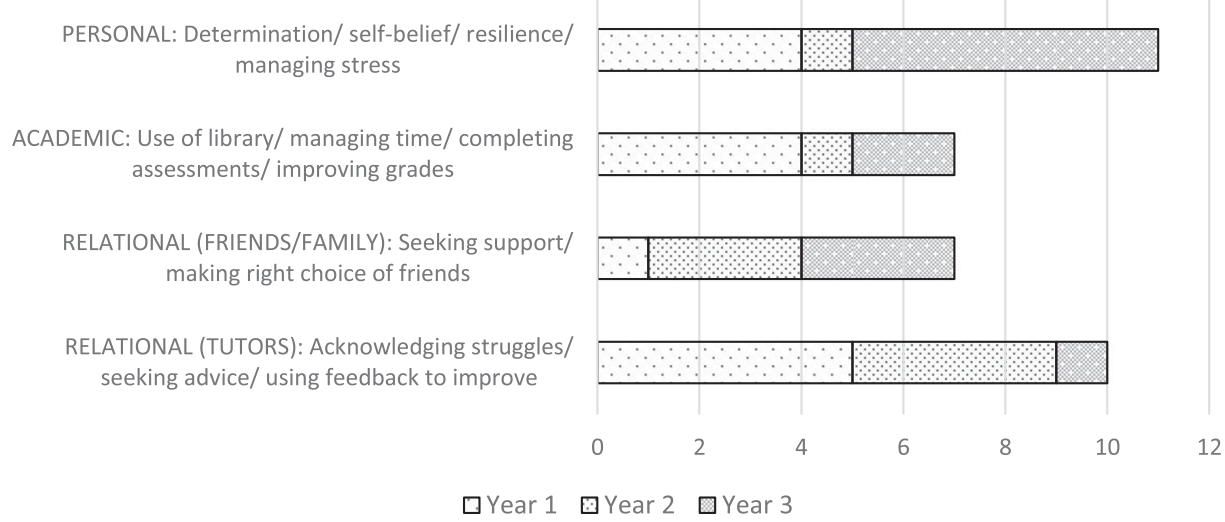

Figure 5. Factors and strategies enabling persistence.

needed to say 'no'. This was a significant issue especially for those whose parents could not afford to subsidise tuition fees. But these students were keen to emphasise the longer-term benefits this strategy had brought, despite the sacrifice of short-term financial gain.

\section{Relational (friendship and family)}

Issues around friendships came to the fore. Considerable emphasis was placed on the inestimable benefit that a network of friends could offer in terms of providing help and support, working together and sharing in times of difficulty. One Year 3 student spoke of the way her friendship group had meant she had 'never felt alone':

Yeah, so like say if one of us is stressed, probably someone else in the group has already felt like that or going through the same thing so to talk about it and support each other through it helps you a lot, because you're not the only person going through it.

Students in their final year also discussed at some length how nervous they had felt when they first started at university, and how friendships had given them confidence to attend. In one student's words:

I don't even remember my first day, I think I was poorly on my first day, well everyone thought I was hung over but I wasn't. I was just really so scared and nervous I was actually poorly. Like if I hadn't had met you in the morning I don't know what would have happened.

Students explained the wider benefits of a network of friends in fostering a sense of belonging and academic engagement:

The sense of belonging makes you want to come in, attend lectures, feel comfortable in group discussions.

Friendship groups had evolved in almost all cases into shared learning groups; students explained that they had engaged with their studies more effectively when they joined together in the library as a group to discuss study tasks or work on assignments. This strategy had also helped to make learning more enjoyable. Support from family members, and having family to turn to in times of need, also featured highly across all year groups.

\section{Relational (tutor and student)}

Interesting discussions took place around tutor support, with emphasis placed as much on pastoral support as academic. A first year student spoke of being able to approach tutors for support: 
There's an open door to speak to tutors one to one. Knowing help is there takes the weight off my shoulders.

Year 3 students reiterated this point, confirming that they had turned to tutors for help and guidance:

The tutors - a massive support, played a huge part in getting me through.

Students were keen to emphasise the value of approaching tutors early on when they were struggling with either academic or personal issues, rather than trying to continue without admitting they needed help. Students in Year 3 expressed regret for not contacting their tutors earlier for support:

I think this year, I've spoken to the tutors in this third year more than I have in the past two years, because I've realised how important they are as a factor to getting my degree.

This supports earlier findings that highlighted the reticence of Year 1 students to approach tutors, due largely to lack of confidence or fear of being regarded as a failure.

\section{Integrative discussion}

Findings from this joint study highlight some important issues relating to student persistence at $\mathrm{HE}$ level. It must, of course, be acknowledged, that these findings relate to students within one faculty in one HE institution - albeit across two separate sites - and therefore cannot be representative of students across other institutions and on other courses. However, valuable lessons can be drawn from the study that may be relevant further afield.

\section{Issues and challenges affecting persistence}

There is no doubt that numerous challenges exist for the student in higher education. These, of course, vary from student to student, and much may depend upon individual circumstances, personal characteristics and prior experiences.

\section{Academic skills and independent study}

Dominating the discussions of Year 1 and 2 students were issues related to HE study such as assignment writing, academic reading, meeting deadlines and time management. The survey similarly identified academic skills as potential issues. Xuereb (2014), in her research into causes of student retention and attrition, found that academic workload and course-related problems were cited by most students as challenging. These, after all, are not innate skills; they need to be acquired. The pressures of these challenges may be due - at least for students in their first year - to the shock of transition from one academic environment to another and having to come to terms with the increased demands of HE study compared to a typical sixth-form college environment. This phenomenon is referred to by Ivins, Copenhaver, and Koclanes (2017) as 'transfer shock', and relates to the confusion that can be felt as students transition into higher education from another academic culture. Transitioning students must develop the skills of independent learning; they need to learn that they need to learn, not merely be taught (Railton and Watson 2005). As Searing and Varcin (2017) point out, students entering university may bring with them learning strategies developed in school that may no longer be relevant; changes in teaching style, requirement for academic reading and the need for self-directed learning may leave them feeling unprepared for the transition.

\section{Confidence, belonging and response to challenge}

For Year 1 and 2 students, there seemed to be a relationship between their levels of confidence and experience of stress. This affected their ability to approach tutors for support, and in speaking or presenting to others within their year group. Bledsoe and Baskin $(2014,33)$ observe the anxiety-induced feelings experienced by students who seem 'almost paralyzed by fear when talking in class'. Some in 
their first year lacked confidence in making friends or approaching peers, fearing rejection; whereas students who were optimistic and open to new experiences appear to adapt their behaviours and thinking in the face of new challenges, ideas and situations. Confidence and a sense of belonging appear to be key to a student's integration to the university environment (Burrus et al. 2013); lack of confidence can seriously hinder a student's progress by deterring them from participation or connecting with others (be it students or tutors) and so missing out on a sense of belonging and connection. The extent to which students regarded themselves as part of 'something bigger' and felt they identified with the institution and included as part of the university system, seemed to correlate with their increasing confidence levels. This idea is supported by Burrus et al. (2013) who recognised students' social and academic integration in terms of belongingness and connection to the university environment as a key factor in their persistence.

There was a significant divide between Year 1 and 2 students and those in their final year. With few exceptions, students in their first and second years tended to respond negatively to the challenges they encountered. However, as students moved into their final year, it was noticeable that they appeared to cope better with stress factors and turned challenging situations into opportunities for improvement; the effect on their studies was generally positive. The different ways in which students responded to challenges may relate to difference in mindset. Dweck's (2008) 'mindset' theory is a useful tool through which these contrasts in responses may be interpreted. She believes that a fixed mindset responds negatively to challenge and a fear of failure, whereas a growth mindset can have a powerful influence on believing that improvement is possible. A setback can be looked upon as an opportunity for improvement rather than a confirmation of failure. Students with a positive attitude to obstacles and challenges are more likely to persist in their studies and prove to be successful.

\section{Factors and strategies enabling persistence}

To students in the study, the term 'persistence' meant never giving up, being determined to succeed, keeping focused and self-motivated and overcoming challenges, always keeping the end goal of a degree in mind. This is in line with Xuereb's (2014) quantitative study on student attrition and retention, which found that students' main reasons for continuing with their studies were to achieve their end goal and to finish what they had started.

\section{Academic engagement}

Those students who were organised in terms of time management, who engaged in research and further reading and who built on previous attainment to improve grades, were better able to cope with the challenges of academic writing and meeting assignment deadlines, and thus succeed in their studies (Kappe and Van der Flier 2012). Students who made use of tutor feedback to improve appeared to be more academically resilient and able to cope with setbacks. They reflected on formative assessment results and tutor feedback to help them identify areas for improvement, and this spurred them on to strive for higher grades in future assignments. Graham and Diez (2015) argue that constructive feedback and feed-forward can help students to become more disciplined in their studies and consolidate prior learning to improve the quality of their work and attain greater academic achievement.

\section{Peer networks and supportive relationships}

A key point that has emerged from the findings is the significance of positive peer networks and the establishment of friendship groups as a means of providing both personal and academic support. On the survey's Factor 3 (Network of Support), 'Access to a supportive network of people' loaded strongest, indicating a relationship between this variable and student persistence. Harper and Quaye (2014) observe that institutional and external communities tend to be made up of a network of people whose support is key to students being persistent. Support from the external ecological environment was important in enhancing student persistence as alluded to by students in this study in response to 
the variable 'My family is supportive of my degree choice'. When they start university, students rely on a network of support for encouragement and inspiration. This can be friends and family who may have encouraged and inspired the student to enrol. Most of the existing body of literature (e.g. Brooks 2010) points to the importance of friends and family in students' initial decisions to commit to a university programme.

However, as the present results indicate, a university-initiated network of support is also helpful for the development of both academic and social belonging particularly in first year of study where students are likely to feel lonely or homesick (Tinto 1999). Friendship groups had in several cases evolved into shared learning communities, where students felt they were less distracted when working together than alone. Ginn et al. (2015) believed that when students are involved in shared learning communities they tend to be more academically and socially engaged, and that this engagement is fundamental to persistence. Friends can provide essential emotional support and act as a buffer against stressful situations - particularly in the absence of close family relationships - but also help their peers to feel part of the social sphere of the university. This was particularly emphasised by students with hidden learning disabilities such as dyslexia, echoing Hamblet's (2015) sentiments that a sense of connection with others can maximise chances for students with disabilities to persist in their degree studies.

Even with a strong network of support, students need intrinsic qualities, such as determination and optimism, to interact with that network of support and set initial goal commitments. As students continued in their learning journey, so there appeared to be a growth in resilience and a move towards greater self-belief and resolve to succeed. Consistent with this, the present study also revealed that there was significant positive relationship between access to a supportive network of people and optimism, further demonstrating the centrality of an interaction between complexly related variables.

It is noteworthy that some students in the study were not able to enjoy the benefits of such close friendship groups, and therefore missed out on collaborative learning sessions, simply due to the constraints of external circumstances such as commuting or parenting responsibilities. Institutions need to take these factors into consideration when seeking to provide a socially and culturally inclusive student experience.

\section{Student-tutor relationships}

Further to this, clear evidence has emerged from the study about the importance of a relational pedagogy of student-tutor relationships, and of students as partners in that relationship. Third year students in this study emphasised this as key to their own persistence and success. Tinto (1999, 2010) argues that the quality of tutor support, in terms of interaction, advice, feedback and involvement, is directly related to the likelihood of students to persist. This relational pedagogy in terms of positive partnerships and interactions between teaching staff and students appears to be vital in terms of student engagement and success (Pearce and Down 2011). Interestingly, students at all levels spoke of their initial apprehensiveness and lack of confidence in feeling able to approach tutors for help - even their own personal tutors. Bledsoe and Baskin $(2014,38)$ suggest this fear is inherent in many students; they speak about the embarrassment, confusion or intimidation students may experience when tutors approach them, either from fear of not knowing what to say, or of being judged as 'too stupid for college'. Students who did seek to build positive relationships with tutors, however, acknowledged that they found them to be understanding and approachable and an immense help both on a personal and academic level.

\section{Concluding remarks and implications for practice}

This study set out to examine factors affecting student persistence and progression and to allow research to inform and transform practice. Findings emerging from the study open up opportunities 
for several possible strategies that could be adopted by the university to enhance student persistence and retention and inversely, to curtail student attrition.

\section{Personal, academic and social integration}

The results highlight the need for systematic personal, academic and social integration strategies to support students' transition (e.g. from a traditional sixth-form college environment to a university degree programme, and also progression to second and final year of study). There was a strong sense that students joining university feared being seen as a failure if they admitted needing help or clarification from a tutor. This should send a strong message to tutors of the importance of developing a culture of approachableness and a nurturing environment both inside and outside the classroom. Tinto's (1997) model of persistence has shown the significant impact that social and academic integration has on student persistence. A closer look at the model will identify the relational interplay between these factors and their effects on the quality of student effort and subsequent learning. Students need to feel they 'fit' and are accepted in order to feel comfortable and confident enough to interact with tutors - and with each other. The value of a relational pedagogy which acknowledges these factors cannot be over-emphasised.

\section{Pastoral approach}

Findings indicate a need for tutors to develop a positive, relational approach towards their tutees and seek to be approachable and readily available to provide academic support. This includes a pastoral approach to teaching and learning; for example, teaching which caters for the student holistically rather than solely through academic-oriented strategies. Examples of such an approach can include: allowing additional time at the end of taught sessions for students who may want to have a quick conversation or debrief with their tutor; or students being taught at least one module by their personal tutor in smaller groups where they are likely to feel confident to participate in seminar sessions, whilst also developing supportive interpersonal relationships and a sense of belonging. As Baumeister and Leary $(1995,155)$ observe, 'human beings are fundamentally motivated by the need to belong, that is, by a strong desire to form and maintain enduring interpersonal attachments', thereby averting feelings of isolation. Interactive learning and teaching strategies offer possibilities for student-student and student-tutor interaction. In addition to timetabled personal tutorials scheduled throughout the year, tutors could also send supportive emails or notes to their tutees and check on the progress of their studies, particularly during significant transition pointsin-time throughout the academic year. Bledsoe and Baskin $(2014,38)$ urge tutors to be proactive in finding ways to communicate with students beyond the classroom: 'Personal relationships between students and instructors can create inroads of trust in the classroom'. Thus, secure interpersonal attachments and academic transition support may have the potential to enhance students' positive adjustment to university whilst also fostering students' self-reliance, self-determination and a resolve to succeed in the face of challenges.

\section{'Growth' mindset}

Results from this study indicate that students with a growth mindset tend to respond positively in the face of academic setbacks (Dweck 2008). Therefore, promoting growth mindset on the tutor's part may enhance persistence in students as they are likely to take academic setbacks as teachable moments and use feedback positively to improve their future assignments. Tutors should be careful to nurture those whose past experiences can create a fixed mindset which may result in feeling unable to move forward when a task becomes overwhelming. Dweck (2008) urges tutors to take care to offer praise - not so much for intelligence or talent as for effort and perseverance in overcoming challenges - aiming to create hardy, resilient students. Bledsoe and Baskin (2014) 
suggest that tutors can help to cultivate these qualities in students, challenging rigid ways of thinking and encouraging students to believe they have the potential to succeed.

\section{Academic curiosity}

Results from this study indicate that students who tend to be 'academically curious' respond positively when they encounter academic setbacks. To enhance academic curiosity, tutors may encourage students to practice self-reflection, reflexivity and critical thinking beyond the confines of the classroom. This may mean integrating reflection into assignment tasks in order to give students opportunities to 'describe their internal processes, evaluate their challenges, and recognise their triumphs in ways that would otherwise remain unarticulated' (Allan and Driscoll 2014, 37). Students who are intellectually stimulated are likely to be 'more satisfied with their university experience and to enjoy their studies' and persist (Stumm, Hell, and Chamorro-Premuzic 2011, 582). Findings also showed that students' self-motivation and persistence with regard to their academic progress was considerably enhanced by the provision of constructive formative feedback and feed-forward from their tutors. Tutor feedback can be used to help students strive for higher grades whilst promoting academic curiosity and a growth mindset (Dweck 2008; Habley, Bloom, and Robbins 2012). This can be further enhanced by the provision of formative feedback that respects students' current levels of performance whilst challenging them to aim higher, thereby fostering motivation.

\section{Delayed gratification}

Findings highlighted that in spite of the challenges they encountered, students stayed on the course due to the perceived benefits of gaining a degree, among other factors. Thus, staying on becomes a function of delayed gratification (Bembenutty 2011) where students have to forego present pleasures for a perceived greater benefit in the distant future. Zayas, Günaydin, and Pandey $(2013,707)$ observe that for persistence to be enhanced, delayed outcomes must be envisioned in order 'to continue working toward the goal and simultaneously inhibit tempting, highly accessible alternative representations' that tend to compete with the determination to achieve the ultimate goal. The university could enhance deferred gratification by creating an academic environment that encourages students to consider their own career aspirations and to set goals and action plans for future employment. There will also be a need to constantly inculcate and reinforce the long-term value of completing the degree. Employability skills need to be embedded into the HE curriculum and integrated into assessment tasks so that students can draw connections between their academic and career goals; in turn they will find greater relevance and value in their course content. Integrated work placements can also provide students with invaluable real-life experiences, allowing them to gain valuable professional skills and opportunities to assess the job market and even lay the foundations for future employment. These strategies may help students envision the delayed outcome and continue to work towards their ultimate goal for the sake of a perceived future benefit, thus making a conscious decision to persist in their studies despite numerous challenges.

\section{Disclosure statement}

No potential conflict of interest was reported by the authors.

\section{References}

Allan, E. G., and D. L. Driscoll. 2014. "The Three-Fold Benefit of Reflective Writing: Improving Program Assessment, Student Learning, and Faculty Professional Development." Assessing Writing 21: 37-55.

Babones, S. 2016. "Interpretive Quantitative Methods for the Social Sciences." Sociology 50 (3): 453-69.

Baumeister, R. F., and M. R. Leary. 1995. "The Need to Belong: Desire for Interpersonal Attachments as a Fundamental Human Emotion." Psychological Bulletin 117: 497-29. 
Bembenutty, H. 2011. "Academic Delay of Gratification and Academic Achievement." New Directions for Teaching and Learning 126 (2): 55-65.

Bledsoe, T. S., and J. Baskin. 2014. “Recognizing Student Fear: The Elephant in the Classroom.” College Teaching 62 (1): $32-$ 41.

Brooks, R. 2010. "Young People's Higher Education Choices: The Role of Family and Friends." British Journal of Sociology of Education 24 (3): 283-97.

Burrus, J., D. Elliott, M. Brenneman, R. Markle, L. Carney, G. Moore, A. Betancourt, et al. 2013. "Putting and keeping students on track: toward a comprehensive model of college persistence and goal attainment." Accessed 9 November 2015. https://www.ets.org/Media/Research/pdf/RR-13-14.pdf.

Calcagno, L., D. Walker, and D. J. Grey. 2017. "Building Relationships: A Personal Tutoring Framework to Enhance Student Transition and Attainment." Student Engagement in Higher Education 1 (2): 88-95.

Callon, M., and J. Law. 1995. "Agency and the Hybrid Collectif." The South Atlantic Quarterly 94/2: 481-507.

Darlington, Y., and D. Scott. 2002. Qualitative Research in Practice: Stories from the Field. Maidenhead: Open University Press.

Dweck, C. 2008. Mindset: The New Psychology of Success. New York: Ballantine.

Farquhar, K., M. Sawyer, C. Cook, and P. Smith. 2006. Enhancing Student Engagement. Accessed 7 May 2017. http://ntrp. org.uk.

Foucault, M. 2010/1972. The Archaeology of Knowledge and the Discourse on Language. Translated by A. M. Sheridan Smith. New York: Vintage Books.

Gallagher, M., S. Haywood, M. Jones, and S. Milne. 2010. "Negotiating Informed Consent with Children in School-Based Research: A Critical Review." Children and Society 24: 471-82.

Ginn, M. H., C. D. Albert, L. Hunter, K. Fitzgerald, and A. Philips. 2015. "Modeling Student Success: How Model UN Programs Can Enhance Performance and Persistence." The Journal of the Georgia Political Science Association 11: 164-95.

Graham, S. E., and M. E. Diez. 2015. "The Complexity of Character: An Ability-Based Model for Higher Education." Journal of Character Education 11 (1): 230-54.

Habley, W. R., J. L. Bloom, and S. Robbins. 2012. Increasing Persistence: Research-Based Strategies for College Student Success. San Francisco: Jossey-Bass.

Hakimi, S., E. Hejazi, and M. G. Lavasani. 2011. "The Relationships Between Personality Traits and Students' Academic Achievement." Procedia - Social and Behavioural Sciences 29: 836-45.

Hamblet, E. C. 2015. "Understand the Myriad Factors Affecting Student Retention." Disability Compliance for Higher Education 20 (9): 1-16.

Harper, S. R., and S. J. Quaye. 2014. "Making Engagement Equitable for Students in U.S. Higher Education." In Student Engagement in Higher Education, edited by S. R. Harper and S. J. Quaye, 1-15. New York: Routledge.

Ivins, T., K. Copenhaver, and A. Koclanes. 2017. "Adult Transitional Theory and Transfer Shock in Higher Education: Practices from the Literature." Reference Services Review 45 (2): 244-57.

Jensen, D. 2008. "Transferability." In The Sage Encyclopedia of Qualitative Research Methods, edited by L. Given, 886-889. Thousand Oaks, CA: Sage.

Kappe, R., and H. Van der Flier. 2012. "Predicting Academic Success in Higher Education: What's More Important Than Being Smart?" European Journal of Psychology of Education 27 (4): 605-19.

Mount, M. K., M. R. Barrick, S. E. Scullen, and J. Rounds. 2005. "Higher Order Dimensions of the Big Five Personality Traits and the Big Six Interests." Personal Psychology 58: 447-78.

Oseguera, L., and B. S. Rhee. 2009. "The Influence of Institutional Retention Climates on Student Persistence to Degree Completion: A Multilevel Approach." Research in Higher Education 50 (1): 546-69.

Pearce, J., and B. Down. 2011. "Relational Pedagogy for Student Engagement and Success at University." The Australian Educational Researcher 38 (4): 483-94.

Railton, D., and P. Watson. 2005. "Teaching Autonomy: 'Reading Groups' and the Development of Autonomous Reading Practices." Active Learning in Higher Education 6 (3): 182-93.

Reason, R. D. 2009. "An Examination of Persistence Research Through the Lens of a Comprehensive Conceptual Framework." Journal of College Student Development 50 (6): 659-82.

Searing, C., and M. Varcin. 2017. "Can the use of Reading Tasks Enhance Students' Confidence in the use of Academic Literature?" Spark: UAL Creative Teaching and Learning Journal 2 (1): 28-38.

Shannon-Baker, P. 2016. "Making Paradigms Meaningful in Mixed Methods Research." Journal of Mixed Methods Research 10 (4): 319-334.

Smith, M., L. Therry, and J. Whale. 2012. "Developing a Model for Identifying Students at Risk of Failure in a First Year Accounting Unit." Higher Education Studies 2 (4): 91-102.

Sobh, R., and C. Perry. 2005. "Research Design and Data Analysis in Realism Research." European Journal of Marketing 40 (12): 1194-209.

Stumm, S. V., B. Hell, and T. Chamorro-Premuzic. 2011. "The Hungry Mind: Intellectual Curiosity Is the Third Pillar of Academic Performance." Perspectives on Psychological Science 6 (6): 574-88. 
Teddlie, C., and A. Tashakkori. 2003. "Major Issues and Controversies in the use of Mixed Methods in the Social and Behavioural Sciences." In Handbook of Mixed Methods in Social and Behavioural Research, edited by C. Teddlie and A. Tashakkori. Thousand Oaks, CA: Sage.

Thomas, L. 2002. "Student Retention in Higher Education: The Role of Institutional Habitus." Journal of Educational Policy 17 (4): 423-42.

Tinto, V. 1997. "Classrooms as Communities: Exploring the Educational Character of Student Persistence." Journal of Higher Education 68 (6): 599-623.

Tinto, V. 1999. "Taking Retention Seriously: Rethinking the First Year of College." NACADA Journal 19 (2): 5-9.

Tinto, V. 2010. "From Theory to Action: Exploring the Institutional Conditions for Student Retention." Higher Education: Handbook of Theory and Research 25 (2): 51-89.

Tinto, V. 2017. "Reflections on Student Persistence." Student Success 8 (2): 1-8.

Xuereb, S. 2014. "Why Students Consider Terminating Their Studies and What Convinces Them to Stay." Active Learning in Higher Education 15 (2): 145-56.

Yin, R. K. 2003. Case Study Research: Design and Methods. 3rd Ed. Thousand Oaks: Sage.

Yorke, M., and B. Longden. 2008. The First Year Experience of Higher Education in the UK. York: Higher Education Academy.

Zayas, V., G. Günaydin, and G. Pandey. 2013. "Persistence: What Does Research on Self-Regulation and Delay of Gratification Have to say?" Behavioural and Brain Sciences 36 (6): 702-7. 